\title{
Coulisses
}

Revue de théâtre

1 | Printemps 1990

Varia

\section{Amal, comédienne au TU}

\section{Amal et Rédaction}

\section{(2) OpenEdition}

\section{Journals}

Édition électronique

URL : http://journals.openedition.org/coulisses/1557

DOI : $10.4000 /$ coulisses. 1557

ISSN : 2546-9460

\section{Éditeur}

Presses universitaires de Franche-Comté

\section{Édition imprimée}

Date de publication : 1 avril 1990

Pagination : 44-46

ISSN : 1150-594X

\section{Référence électronique}

Amal et Rédaction, «Amal, comédienne au TU », Coulisses [En ligne], 1 | Printemps 1990, mis en ligne le 04 juillet 2017, consulté le 23 octobre 2019. URL : http://journals.openedition.org/coulisses/1557 ; DOI : 10.4000/coulisses. 1557

Ce document a été généré automatiquement le 23 octobre 2019

Coulisses 


\title{
Amal, comédienne au TU
}

\author{
Amal et Rédaction
}

1 Amal a vingt ans, elle est en deuxième année de LEA (Langues étrangères appliquées) à l'UFR de Lettres de Besançon.

2 A. : Je suis inscrite au TU depuis un an seulement et je joue dans le spectacle que l'on a travaillé l'an dernier (Mystère Bouffe). Parler de mes motivations est un peu difficile... en fait, j'ai toujours aimé le théâtre. Il m'apporte beaucoup parce que c'est déjà un moyen, pour moi, de sortir un peu. Tu sais, avec le boulot, on a souvent tendance à s'enfermer. Là, on rencontre des gens et puis jouer devant des spectateurs, c'est passionnant. À un moment donné, $j$ 'aurais aimé faire une carrière mais c'est un milieu où tu es trop peu sûre de réussir. Moi, je préfère assurer mes études et faire du théâtre à côté. C. : Certains étudiants préparent l'examen d'entrée à l'école du Théâtre National de Strasbourg?

A. : Oui, il y a Gilles, Patricia, Faïza je crois. C'est un examen très difficile.

C. : Qu'éprouves-tu quand tu joues?

6 A. : Bon, je vais peut-être te paraître bizarre mais je dois dire que je n'ai pas vraiment le trac. Juste avant d'entrer en scène, j'ai une petite appréhension, un petit nœud mais après c'est bien, surtout lorsque les spectateurs réagissent. Par contre, s'il n'y a aucune réaction de leur part, c'est terrible. En fait, c'est ça qui est intéressant, tu ne sais jamais comment les gens vont réagir par rapport à tes actions.

7 C. : Parle-moi de l'ambiance de la troupe?

8 A. : À mon arrivée, c'était un peu difficile parce que je ne connaissais personne. C'est toujours comme ça quand tu commences une amitié avec quelqu'un. Au début, il n'y a rien du tout, tu ne sais même pas de quoi parler, et puis, petit à petit, il y a des liens qui se créent avec certaines personnes; bon, pas avec toutes, parce que évidemment on ne peut pas s'entendre avec tout le monde, il faut être réaliste. Mais je dirais qu'en général, l'ambiance est plutôt bonne.

C. : Quel est le profil des étudiants qui sont dans ton groupe?

A. : Au niveau de l'âge, ça va de 19 à 50 ans, je crois. Certains sont à la fac de lettres, d'autres en Sciences ou alors à l'Université Ouverte. 


\section{C. : Qu'est-ce que tu ressens quand tu regardes les autres jouer?}

A. : Je suis épatée. Je les trouve très bons. Au début, ils m'intimidaient même un peu parce que c'était ma première année et que j'avais beaucoup de mal à jouer et à prendre un personnage. Je me sentais parfois ridicule vis à vis d'eux. Il faut dire que dans notre groupe, la plupart des gens jouent au moins depuis deux ans, ils ont donc plus d'expérience. Quand on n'est pas très sûr de soi, on a toujours tendance à croire que l'on vous juge et puis après ça passe. Ce qui est bien, c'est de voir jouer les autres et de remarquer qu'il nous font toujours autant rire. Pourtant, les scènes nous les avons vues je ne sais pas combien de fois. Vraiment, on ne se lasse pas et je crois que plus on les voit, plus on les trouve bien faites.

\section{C. : Quels sont les personnages que tu aimerais jouer?}

A. : J'aurais aimé jouer, non pas un personnage particulier dans Dario Fo, mais un personnage avec beaucoup de caractère, plutôt du tragique. Je veux dire que si j'avais eu à choisir, je ne sais pas si j'aurais opté pour l'Ange par exemple. Bon, je pense que si Joseph m'a confié ce rôle, c'est qu'il avait ses raisons. Le fait de choisir son personnage ne veut pas dire que nous ayons les capacités nécessaires pour le jouer. Dans un sens c'est mieux comme ça.

\section{C. : Quand tu vois d'autres pièces, jouées par d'autres comédiens, comment réagis-tu?}

A. : Tu sais, on a un esprit un peu critique. Moi, j'ai remarqué que je faisais beaucoup plus attention au jeu de l'acteur. Par exemple, quand je suis allée voir La Savetière, j'ai trouvé que l'actrice jouait bien certes, mais qu'elle avait toujours la même tonalité dans la voix. Je pense que c'est une bonne expérience parce que cela nous permet d'aborder une pièce sous un autre angle. On la voit différemment, je n'oserais pas dire en tant qu'acteur, mais en tout cas seulement comme spectateur. C'est peut-être dû au fait qu'au TU, on ne se contente pas de jouer, on regarde jouer les autres aussi et on leur donne des indications. C'est très intéressant ça parce que l'on a toujours besoin de regards extérieurs, ça nous apporte énormément.

C. : Quel est le rôle d'un acteur vis à vis de son public?

A. : Il faut faire passer un message. Quel que soit le genre de pièce, il faut que cela apporte quelque chose aux gens. Par exemple, si on joue du comique, c'est pour que les spectateurs ressentent une certaine joie à un certain moment, pour qu'ils oublient ce qu'il y a en dehors de la scène, pour qu'ils vivent vraiment avec nous. C'est comme si le public jouait avec les comédiens en quelque sorte. Je dois avouer qu'au début je ne pensais jamais vraiment à ça. Je regardais toujours par rapport à moi, par rapport à ce que cela pouvait m'apporter... sortir, m'extérioriser, faire autre chose. Tu sais, dans la vie quotidienne, on est toujours plein d'émotions que l'on est obligé de cacher. Au théâtre par contre, tu peux vraiment être toi-même et pas seulement toi-même parce que tu peux être amené à jouer des personnages qui ne te ressemblent pas forcément.

C. : Mais le rôle de l'acteur n'est-il pas de pouvoir incarner n'importe quel personnage?

A. : Oui, je crois que c'est pouvoir s'adapter à toutes les situations. Un comédien, c'est plusieurs personnages en un seul. À mon avis, les vrais comédiens sont des gens très complexes.

\section{C. : Quels sont les acteurs que tu apprécies?}

A. : Oh, les noms... Prenons le problème autrement. Le cinéma par exemple, ne m'a jamais vraiment intéressée. J'ai l'impression que c'est artificiel, on ne demande pas tout 
à fait à l'acteur d'être performant... les scènes, on les coupe, on les replace. Le théâtre, c'est différent car jouer sur une scène, devant un public, pendant deux heures, ça c'est difficile.

23 C. : Tu n'as pas d'acteurs préférés alors?

24 A. : Si, j'aime bien Lambert Wilson et en plus il fait du théâtre. Il est difficile de te répondre parce que je n'ai jamais été «fan » d'une personne particulière. 